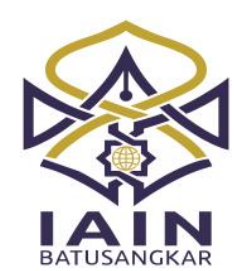

JURNAL TA'DIB, Vol 22 (1), 2019, (Januari-Juni)

ISSN: 1410-8208 (Print) 2580-2771 (Online)

Tersedia online di http://ecampus.iainbatusangkar.ac.id/ojs/index.php/takdib/index

\title{
Efektivitas Mentoring terhadap Pengamalan Keagamaan Mahasiswa Fakultas Keguruan dan Ilmu Pendidikan Universitas Sriwijaya Palembang
}

\author{
Nurlaila*) \\ Universitas Islam Negeri Raden Fatah \\ Palembang \\ Email:nurlaila_uin@radenfatah.ac.id

\section{Enok Rohayati} \\ Universitas Islam Negeri Raden Fatah \\ Palembang \\ Email: enokrohayati_uin@radenfatah.ac.id
}

*) Corresponding Author

\begin{abstract}
Abstrak: The purposes of the study are to describe the implementation of mentoring program and religious practice, and to find out the effectiveness of the mentoring program on student religious practice. This is a mixed qualitative quantitative research. The results show that Islamic Education mentoring activities in increasing religious practice had achieved overall success, amounting to 90\%. The mentoring program can achieve the objectives planned previously. The effectiveness of the mentoring program is indicated by a tcount of 7.343> $1.70 \mathrm{t}$ table, with the level of significance $0.00<0.05$. From the results of the descriptive analysis, it was found that the percentage of mentoring activities was $75 \%$ and the percentage of religious practice was $83 \%$.. It can be summarized that Mentoring activities of Islamic Religion are effectively carried out to foster student religious practice at Teaching and Education Faculty of Sriwijaya University Palembang.
\end{abstract}

Kata Kunci: Monitoring Program, Religious Practice, Islamic Education

\section{PENDAHULUAN}

$\mathrm{K}$ egiatan mentoring Pendidikan Islam adalah salah satu strategi pembinaan ke-Islaman bagi mahasiswa yang dilakukan melalui halaqah-halaqah (lingkaran kelompok kecil). Program ini diselenggarakan dalam rangka mengembangkan potensi dan fitrah keagamaan mahasiswa pada universitas sebagai tanggung jawab moral dan komitmen untuk mewujudkan kampus yang berwacana keilmuan dan ke-Islaman. Tujuan umum dari program ini adalah mendampingi dan mengarahkan mahasiswa dalam mengkaji dan mengaplikasikan nilai-nilai keislaman dalam dirinya (Shobahiya, 2008).

Mahasiswa sebagai agen perubahan diharapkan memiliki konsep diri yang positif. Konsep diri yang positif pada mahasiswa dapat dibentuk dengan meningkatkan religiusitas melalui peran teman sebaya (significant other). Konsep diri merupakan persepsi seseorang terhadap dirinya sendiri, dimana persepsi ini dibentuk melalui pengalaman dan interprestasi seseorang terhadap dirinya. Salah satu program yang dapat dilakukan adalah melalui mentoring agama Islam (Setiawan, 2013). Mentoring agama Islam adalah salah satu metode pendidikan Islam yang dilaksanakan secara rutin tiap minggu dalam sebuah kurikulum tertentu.

Universitas merupakan lembaga formal penyelenggara pendidikan yang bertugas untuk membangun kecerdasan generasi muda. Kecerdasan yang diharapkan bukan hanya kecerdasan intelektual saja, tetapi juga kecerdasan emosional dan spiritual. Pendidikan menjadi wadah tejadinya proses transfer ofknowledge, skill, dan value (Walid, 2011). Ketiga hal tersebut bukan hanya didapatkan mahasiswa di kelas, dapat 
juga terbangun melalui kultur yang berkembang dan diaplikasikan kepada mahasiswa dalam berbagai program strategis universitas.

Kultur yang berkembang di universitas menjadi faktor penting dalam pembentukan karakter mahasiswa. Pembentukan karakter tergantung kepada orang-orang yang membentuknya dan situasi lingkungan yang mendukungnya (Ainiyah, 2013). Kondisi lingkungan yang membentuk kepribadian baik tentu akan menjadi pribadi yang baik, begitu juga dengan lingkungan yang buruk tentu akan terbentuk pribadi yang buruk.

Karakter tidak sekedar mengajarkan tentang hal mana yang benar dan mana yang salah kepada anak, tetapi lebih dari itu karakter ditanamkan melalui pembiasaan (habituation) tentang nilai-nilai kebaikan sehingga mahasiswa dapat memahami, merasakan, dan mau melakukan hal yang baik. Modal dasar perbaikan karakter adalah pemahaman agama. Tidak dapat dipungkiri bahwa penanaman karakter tidak bisa terlepas dari nilai-nilai agama. Agama memainkan peran dan tanggung jawab yang sangat besar dalam mewujudkan tujuan pendidikan nasional (Sudaryanti, 2014).

Sesuai dengan amanat Undang- Undang Sistem Pendidikan Nasional Nomor 20 Tahun 2003 pasal 3 yang menjelaskan bahwa pendidikan nasional berfungsi mengembangkan kemampuan dan membentuk watak serta peradaban bangsa Indonesia yang bermartabat dalam rangka mencerdaskan kehidupan bangsa, bertujuan untuk mengembangkan potensi peserta didik agar menjadi manusia yang beriman dan bertaqwa kepada Tuhan Yang Maha Esa, berakhlak mulia, sehat, berilmu, cakap, kreatif, mandiri dan menjadi warga negara yang demokratis serta bertanggung jawab (Penyusun, 2003).

Mentoring yang diterapkan di Fakultas Keguruan dan Ilmu Pendidikan Universitas Sriwijaya Palembang adalah salah satu strategi pembinaan pengamalan keagamaan bagi mahasiswa yang dilakukan melalui lingkup yang lebih kecil (kelompok kecil).
Kelompok kecil tersebut mendapat bimbingan dari pembimbing. Program ini dilaksanakan dalam rangka mengembangkan sikap, nilai, dan perilaku sebagai proses penanaman karakter pada siswa.

Tujuan umum dari program ini adalah mendampingi dan mengarahkan mahasiswa dalam mengkaji dan mengaplikasikan pengamalan keagamaan dalam dirinya sehingga memiliki budi pekerti atau karakter mulia yang ditunjang dengan penguasaan ilmu dengan baik yang kemudian mampu mengamalkan ilmunya dengan tetap dilandasi oleh iman yang benar. Mentoring Pendidikan Agama Islam di Fakultas Keguruan dan Ilmu Pendidikan Universitas Sriwijaya Palembang pada awalnya tahun 1986 merupakan mentoring biasa, sejak tahun 2008 sebagai program Asistensi Mata Kuliah Pendidikan Agama Islam (AMKAI).

Fakultas Keguruan dan Ilmu Pendidikan Universitas Sriwijaya Palembang dalam proses penyelenggaraan pendidikan berupaya menanamkan pengamalan keagamaan melalui sebuah program mentoring keagamaan. Pengorganisasian program mentoring dilakukan dengan membentuk tim pengelola yang merupakan mahasiswa. Berdasarkan Standar Operasional Pelaksanaan Mentoring Fakultas Keguruan dan Ilmu Pendidikan Universitas Sriwijaya Palembang, komponen dalam program mentoring harus tersedia pengelola mentoring, mentor, kurikulum, dan juga sistem penilaian program mentoring.

Program mentoring agama Islam merupakan salah satu program ekstrakurikuler wajib untuk mahasiswa. Hal ini bertujuan agar ada pembiasan sejak dini sehingga Mahasiswa terbiasa dengan Pengamalan Keagamaan di kesehariannya. Program mentoring ini menjadi salah satu sarana untuk membentuk karakter mahasiswa serta pengamalan keagamaan, oleh sebab itu perlu dilakukan sebuah penelitian mengenai pelaksanaan program mentoring Pendidikan Agama Islam dalam mencapai tujuan tersebut. 
Kegiatan mentoring merupakan salah satu kegiatan pendidikan agama Islam di Universitas Sriwijaya dan diselenggarakan atas kerjasama mentor dan mentee (peserta mentoring) dengan mahasiswa yang tergabung dalam suatu organisasi yaitu Nadwah UNSRI. Kegiatan mentoring dilaksanakan seminggu sekali dan diikuti oleh mahasiswa. Dalam Nadwah terdapat suatu divisi yang disebut PM (Pengelola mentoring). Kebijakan didasari implementasi dari mata kuliah Agama Islam mengalami kendala karena salah satu kendala diantaranya materi yang tercakup dalam mata kuliah Agama Islam tersebut sangat banyak mencakup bidang ibadah syari'ah, akidah-akhlak, tafsir-hadist, sejarah kebudayaan Islam dan bahasa Arab, dengan porsi waktu yang sangat singkat yakni 2 SKS selama satu semester. Salah satu alternatif untuk mengatasi permasalahan tersebut yakni dengan mengadakan kegiatan pendampingan atau mentoring (Penyusun, 2014).

Pengelola mentoring bertugas mengelola kegiatan mentoring dari awal sampai akhir. Tujuan kegiatan mentoring tersebutyaitu 1) Membentuk mahasiswa yang tidak hanya cerdas secara intelektual tetapi juga cerdas secara emosional dan spiritual; 2) Membantu penguasaan baca tulis Alquran; 3) Membantu penguasaan dan penyempurnaan amalan bersuci dan salat; 4) Membantu perbaikan akhlak dan moral mahasiswa; dan 5) Membantu dan memotivasi mahasiswa agar mampu berprestasi sesuai dengan bakat dan minatnya namun tetap berpegang teguh pada ajaran Islam (Penyusun, 2006).

Fenomena yang terjadi pada generasi penerus, terutama di Universitas Sriwijaya Palembang, semakin sepi dari bacaan ayatayat suci Alquran. Hal ini disebabkan karena terdesak dengan munculnya berbagai produk sain dan tehnologi serta derasnya arus budaya asing yang semakin menggeser minat untuk belajar membaca Alquran sehingga banyak mahasiswa tidak bisa membaca Alquran. Akhirnya, kebiasaan membaca
Alquran ini sudah mulai langka. Yang ada adalah suara-suara radio, TV, Tape recorder, karoake, dan lain-lain. Keadaan seperti ini adalah keadaan yang sangat memprihatinkan. Hampir semua Mahasiswa UNSRI Palembang, berasal dari tamatan atau alumni SMAN/SMA swasta lainnya. Untuk itu, mereka sangat perlu bimbingan dalam BTA dan kajian ke-Islaman seperti kegiatan Mentoring, salah satunya BTA dan diadakan workshop tentang ke-Islaman.

Latifah (2016) dalam temuannya bahwa kegiatan mentoring dapat mempengaruhi perilaku sosial keagamaan seseorang, tingkat keberagamaan (Wahyudi, 2012). Dalam temuan lain, mentoring berdampak positif jika dilaksanakan dengan maksimal ditambah dengan model pembelajaran yang baik (Basori, 2013).

Mentoring Agama Islam (MAI) merupakan pembinaan akhlak dengan sistem kelompok kecil. Pada bahasa Arab mentoring dikenal juga dengan halaqoh (lingkaran) atau liqo' (pertemuan). Mentoring Agama Islam adalah pembinaan akhlak dengan sistem kelompok kecil (small group environment), dengan didukung kegiatan-kegiatan penunjang yang diperuntukkan bagi peserta didik, yang merupakan kelompok kecil dan membahas tentang keislaman secara rutin. Anggota kelompok mentoring berjumlah 3-12 orang dan memiliki kurikulum tertentu, sesuai dengan lembaga yang menaungi mentoring tersebut (Luthfiani, 2017).

Rusmiyanti dalam bukunya mendefinisikan Mentoring Agama Islam sebagai suatu kegiatan pembinaan pemuda pelajar yang berlangsung secara periodik dengan bimbingan seorang mentor. Pola pendekatan yang dipakai dalam kegiatan mentoring ialah pola pendekatan teman sebaya (friendship) sehingga lebih menarik, efektif, serta memiliki keunggulan tersendiri (Kurniawati, 2015).

\section{METODE PENELITIAN}

Jenis penelitian ini adalah penelitian kuantitatif kualitatif (mixedmethods). Subjek 
penelitian ini sebanyak 41 orang terdiri dari 40 peserta dan 1 mentor. Pengumpulan data menggunakan observasi, angket yang terlebih dahulu dilakukan uji coba validitas dan reliabilitas, wawancara, dan dokumentasi. Strategi mixed methods menggunakan eksplanatoris sekuensial. Analisis data menggunakan analisis kuantitatif kualitatif yang dilakukan secara bertahap. Analisis data kuantitatif menggunakan statistik deskriptif dan uji t, sedangkan analisis data kualitatif menggunakan teknik triangulasi data.

\section{HASIL DAN PEMBAHASAN Hasil Penelitian \\ Analisis Data Deskriptif}

Dari hasil observasi ditemukan berbagai fakta. Pertama, pelaksanaan program mentoring pendidikan agama Islam. Program mentoring Pendidikan Agama Islam dilakukan pada bidang keagamaan. Berbagai aspek yang dilaksanakan meliputi 6 bidang, yaitu: (1) pengajaran syahadat, meliputi lafal, makna, dan rukun syahadat; ma'rifatullah dan ma'rifatul Islam, meliputi pengajaran sifat-sifat Allah, asmaul husna, rukun iman, dan rukun Islam; (3) ma'rifatul rasul, meliputi pengajaran sifat-sifat Rasul, tugas Rasul, wahyu, hadis, dan sunah; (4) pengajaran BTA (Baca Tulis Alquran), meliputi: iqro', tahsin, dan tahfiz; (5) Fikih, meliputi: salat, taharah, dan wudu; dan (6) grandopening program mentoring, meliputi pelatihan mentor dan pembinaan kader. Keenam bidang tersebut pada umumnya termasuk dalam materi Asistensi Mata Kuliah Agama Islam (AMKAI), salah satu mata kuliah keagamaan di Universitas Sriwijaya.

Petugas yang melaksanakan program mentoring Pendidikan Agama Islam di FKIP Universitas Sriwijaya Palembang adalah mahasiswa yang diangkat sebagai mentor oleh Dekan. Mentor sebelumnya dibina melalui pelatihan mentor oleh penanggungjawab mentoring yaitu dosen Pendidikan Agama Islam Mereka dibagi ke dalam beberapa kelompok dan dikoordinatori oleh mahasiswa.

Kegiatan mentoring Pendidikan Agama Islam berlangsung selama sekali dalam sepekan yang dilakukan setiap jam AMKAI yang diterima oleh mahasiswa selaku mentee. Aktivitas keagamaan dapat berlangsung pada tempat dan waktu yang berbeda dari jadwal sesuai dengan kesepakatan antara mentee dengan mentor.

Kedua, pengamalan keagamaan mahasiswa yang diobservasi adalah pengamalan yang nampak melalui pengamatan. Pengamalan keagamaan mahasiswa, yaitu (1) salat, meliputi tata cara salat, pelaksanaan salat, dan waktu salat, (2) taharah, meliputi: Wudu, menjaga lingkungan/sampah, kebersihan anggota tubuh, (3) hubungan dengan teman, meliputi cara berteman dan bersilaturahmi, (4) ada berkomunikasi dengan dosen, meliputi adab ketika bertemu dan adab ketika bertugas, dan (5) adab berpakaian, meliputi: cara berpakaian dan kebersihan pakaian.

Pengamalan keagamaan yang diamati dari mahasiswa alumni mentoring Pendidikan Agama Islam adalah 25 orang $(62,5 \%)$ mahasiswa salat ketika mendengar suara azan, 10 orang (25\%) salat dengan telah berada di masjid sebelum azan, dan 5 orang $(12,5 \%)$ salat tidak tahu waktunya. Dari 40 orang mahasiswa yang diteliti, pelaksanaan salat 22 orang $(55 \%)$ salat berjamaan, dan 18 orang $(45 \%)$ sendirisendiri. Data observasi tentang taharah, menghasilkan data yaitu wudu dengan benar ada 25 orang $(62,5 \%), 10$ orang $(25 \%)$ wudu ada yang belum benar, dan 5 orang $(12,5 \%)$ belum benar atau tidak sesuai dengan ajaran sunah. Mahasiswa menjaga lingkungan/sampah, kebersihan tangan dan badan, kebersihan pakaian, hubungan dengan teman, meliputi cara berteman dan bersilaturahmi, hubungan dengan dosen, meliputi adab ketika bertemu dan adab ketika bertugas, dan Adab berpakaian, meliputi: cara berpakaian dan kebersihan pakaian. 


\section{Analisis Data Angket}

Angket diisi oleh 40 orang responden yang telah dipilih berdasarkan pertimbangan mahasiswa yang telah mengikuti program mentoring Pendidikan Agama Islam minimal 1 tahun. Jawaban angket berkaitan dengan program mentoring keagamaan diperoleh adalah; Pertama, menumbuhkan rasa cinta untuk mempelajari Islam. Indikator aktivitas mentoring keagamaan yang pertama adalah menumbuhkan rasa cinta terhadap ajaran Islam dengan cara gemar mempelajari ajaran-ajaran Islam. Mempelajari ajaranajaran Islam merupakan suatu usaha yang harus dilakukan oleh setiap muslim. Mahasiswa peserta mentoring sebagai pemeluk agama, berkewajiban untuk senantiasa mempelajari Islam. Melalui mentoring keagamaan, mahasiswa dapat mempelajari materi tentang ajaran Islam secara mendalam. Hasil angket tentang pengamalan keagamaan pada indikator menumbuhkan rasa cinta untuk mempelajari Islam sebesar 94,6\%. Hal ini berarti mahasiswa peserta mentoring mayoritas memiliki rasa cinta yang sangat tinggi dalam mempelajari Islam melalui program mentoring.

Kedua, meningkatkan pemahaman Islam yang benar sesuai alquran dan Sunah Rasulullah Saw. Pemahaman mahasiswa terhadap ajaran Islam yang benar sesuai dengan ajaran Alquran dan hadis merupakan suatu hal yang penting ditumbuhkan karena mempengaruhi kualitas pengamalan terhadap ajaran agama. Mentoring keagamaan mempunyai tujuan untuk meningkatkan pemahaman Islam mahasiswa yang benar sesuai Alquran dan Sunah Rasulallah Saw. Hasil angket menunjukkan bahwa pemahaman terhadap ajaran Islam mahasiswa peserta mentoring keagamaan sebesar 90,8\%. Hal ini menunjukkan bahwa pemahaman mahasiswa terhadap ajaran Islam masuk kategori sangat tinggi.

Ketiga, sebagai partner dosen dalam membentuk mahasiswa yang prestatif dan berkepribadian Islam. Mentoring keagamaan mempunyai program untuk menjadikan kegiatan ini sebagai salah satu partner dosen dalam membentuk mahasiswa yang prestatif dan berkepribadian Islam. Melalui program ini, mahasiswa didik, dibimbing, diarahkan, dan dituntun agar memiliki kepribadian yang Islami sesuai dengan ajaran agama. Apabila pada proses pembelajaran di kelas, mahasiswa hanya memperoleh materi pendidikan agama dengan alokasi yang relatif singkat, maka diharapkan melalui kegiatan mentoring keagamaan dosen mampu mewujudkan mahasiswa yang berkepribadian Islami dengan waktu tambahan dan metode pendampingan, artinya mentoring keagamaan berfungsi sebagai program pendampingan pada mata kuliah keagamaan di FKIP Universitas Sriwijaya Palembang. Hasil angket tentang aktivitas mentoring sebagai partner dosen dalam membentuk mahasiswa yang prestatif dan berkepribadian Islam adalah 95\%. Hal ini menunjukkan bahwa aktivitas sebagai mentoring masuk kategori sangat tinggi.

Keempat, mempererat persaudaraan antar mahasiswa mentoring. Aktivitas mentoring pendidikan agama Islam yang telah dilakukan bertujuan untuk mempererat persaudaraan antar mahasiswa mentoring FKIP UNSRI Palembang. Persaudaraan termasuk ajaran Islam yang penting ditanamkan pada mahasiswa sebagai generasi penerus. Ajaran Islam mengajarkan agar antar pemeluk agama Islam memiliki rasa persaudaraan yang tinggi. Melalui program mentoring, setiap mahasiswa diharapkan dapat menumbuhkan rasa persaudaraan, terutama antar peserta mentoring. Hasil angket menunjukkan persentase sebesar $85,8 \%$. Hal ini berarti rasa persaudaraan yang ditumbuhkan antar peserta mentoring melalui kegiatan ini telah tergolong tinggi.

Kelima, menjadikan program mentoring sebagai sarana kaderisasi pelajar muslim untuk mau bergerak menyeruh pada yang ma'ruf dan mencegah yang munkar. Program mentoring Pendidikan Agama Islam, bertujuan sebagai sarana kaderisasi pelajar muslim untuk mau bergerak menyeruh pada 
yang ma'ruf dan mencegah yang munkar. Kaderisasi merupakan sebuah upaya yang dilakukan untuk menjaga silaturahim dan persatuan serta keberlanjutan program mentoring pendidikan agama Islam. Hasil angket yang telah dilakukan menunjukkan persentase sebesar $91,7 \%$, yang berarti bahwa mentoring Pendidikan Agama Islam sebagai sarana kaderisasi pelajar muslim masuk kategori sangat tinggi.

Keenam, meningkatkan intelektualitas mahasiswa baik dalam bidang keagamaan, akademik dan non akademik. Intelektualitas yang tinggi yang dimiliki mahasiswa merupakan potensi yang penting untuk meningkatkan kualitasnya. Melalui kecerdasan intelektual, mahasiswa dapat menyelesaikan berbagai permasalahan yang penting dalam hidupnya, mampu mengambil keputusan, serta mampu mandiri dalam menjalani kehidupan. Hasil angket menunjukkan bahwa aktivitas mentoting dalam meningkatkan intelektualitas siswa baik dalam bidang keagamaan, akademik dan non akademik adalah sebesar 92,5\% dengan kategori sangat tinggi.

Dari hasil angket yang telah diperoleh menunjukkan hasil yang rata-rata sangat tinggi. Lebih jelasnya, jawaban angket dari semua indikator aktivitas mentoring Pendidikan Agama Islam dapat dilihat pada tabel berikut:

Tabel 1. Deskripsi Data Angket Aktivitas Mentoring Pendidikan Agama Islam

\begin{tabular}{|c|c|c|c|c|}
\hline No & Indikator & Y (3) & KK (2) & $\%$ \\
\hline 1 & Menumbuhkan rasa cinta untuk mempelajari Islam & 33 & 7 & $94,6 \%$ \\
\hline 2 & $\begin{array}{l}\text { Meningkatkan pemahaman Islam yang benar sesuai Alquran dan } \\
\text { Sunah Rasulullah saw. }\end{array}$ & 29 & 11 & $90,8 \%$ \\
\hline 3 & $\begin{array}{l}\text { Sebagai partner guru dalam membentuk pelajar yang prestatif dan } \\
\text { berkepribadian Islam }\end{array}$ & 34 & 6 & $95 \%$ \\
\hline 4 & $\begin{array}{l}\text { Mempererat persaudaraan antar mahasiswa mentoring FKIP } \\
\text { UNSRI Palembang }\end{array}$ & 23 & 17 & $85,8 \%$ \\
\hline 5 & $\begin{array}{l}\text { Menjadikan program mentoring sebagai sarana kaderisasi pelajar } \\
\text { muslim untuk mau bergerak menyeruh pada yang ma'ruf dan } \\
\text { mencegah yang munkar }\end{array}$ & 30 & 10 & $91,7 \%$ \\
\hline 6 & $\begin{array}{l}\text { Meningkatkan intelektualitas siswa baik dalam bidang keagamaan, } \\
\text { akademik dan non akademik }\end{array}$ & 31 & 9 & $92,5 \%$ \\
\hline & Jumlah & 180 & 60 & - \\
\hline & Skor maksimum & 240 & 240 & - \\
\hline & Persentase (\%) & $75 \%$ & $25 \%$ & - \\
\hline
\end{tabular}

Berdasarkan tabel di atas, diketahui bahwa secara keseluruhan data angket aktivitas mentoring Pendidikan Agama Islam mahasiswa adalah $75 \%$ ya dengan makna bahwa mentoring mampu mencapai indikator di atas dan 25\% kadang-kadang dengan makna bahwa mentoring mampu mencapai sebagian indikator di atas. Data mentoring dan pengamalan keagamaan dalam penelitian ini dikumpulkan menggunakan angket yang disebarkan pada mahasiswa yang menjadi sampel dalam penelitian ini. Hasil yang diperoleh, kemudian digunakan dianalisis menggunakan statistik deskriptif. Mentoring Pendidikan Agama Islam dikatakan tinggi apabila $\geq$ median, dan dikatakan rendah apabila $<$ median. Berikut hasil analisis data yang diperoleh.

Tabel 2. Data Mentoring Pendidikan Agama Islam

\begin{tabular}{|c|c|c|c|}
\hline \multicolumn{3}{|c|}{ Statistics } \\
\hline \multicolumn{2}{|c|}{} & Mentoring & Pengamalan Keagamaan \\
\hline \multirow{2}{*}{$\mathrm{N}$} & Valid & 40 & 40 \\
\cline { 2 - 4 } & Missing & 0 & 0 \\
\hline \multicolumn{2}{|c|}{ Mean } & 46,08 & 34,98 \\
\hline \multicolumn{2}{|c|}{ Median } & 47,00 & 36,50 \\
\hline \multicolumn{2}{|c|}{ Mode } & 47 & $37^{\mathrm{a}}$ \\
\hline \multicolumn{2}{|c|}{ Sum } & 1843 & 1399 \\
\hline
\end{tabular}

Berdasarkan tabel di atas, diketahui bahwa nilai mean mentoring Pendidikan Agama
Islam adalah 46,08, median 47, dan modus 47. Data ini mengungkapkan bahwa 
mentoring Pendidikan Agama Islam masuk kategori tinggi. Deskripsi frekuensi data mentoring Pendidikan Agama Islam dapat dilihat pada tabel di bawah ini.

Tabel 3. Deskripsi Frekuensi Data Mentoring Pendidikan Agama Islam

\begin{tabular}{|c|c|c|c|c|c|}
\hline & & Frekuensi & $\%$ & Valid (\%) & Kumulatif (5) \\
\hline \multirow{3}{*}{ Valid } & Tinggi $\geq 47$ & 26 & 65,0 & 65,0 & 100,0 \\
\hline & Rendah $<47$ & 14 & 35,0 & 35,0 & 35,0 \\
\hline & Total & 40 & 100,0 & 100,0 & \\
\hline
\end{tabular}

Berdasarkan data di atas, diketahui bahwa kegiatan mentoring Pendidikan Agama Islam yang diperoleh siswa kategori tinggi 26 grafik di bawah ini:

orang $(65 \%)$ dan kategori rendah 14 orang (35\%). Lebih jelasnya dapat dilihat pada

\section{DATA PERSENTASE MENTORING} KEAGAMAAN

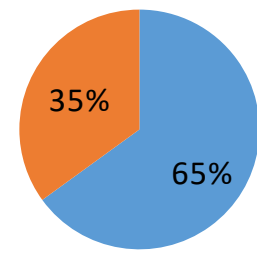

Rendah

Grafik 1. Data Presentasi Mentoring Keagamaan

Sedangkan hasil angket pengamalan keagamaan mahasiswa FKIP UNSRI adalah sebagai berikut.

Tabel 4. Deskripsi Data Pengamalan Keagamaan

\begin{tabular}{|l|l|l|l|l|}
\hline No & Indikator & $\begin{array}{l}\mathbf{Y} \\
(3)\end{array}$ & $\begin{array}{l}\mathbf{K} \\
(\mathbf{2})\end{array}$ & $\mathbf{\%}$ \\
\hline 1 & Keyakinan & 31 & 9 & $92,5 \%$ \\
\hline 2 & Praktek keagamaan & 33 & 7 & $94,6 \%$ \\
\hline 3 & Pengalaman keagamaan & 36 & 4 & $96,7 \%$ \\
\hline 4 & Pengetahuan agama & 29 & 11 & $90,8 \%$ \\
\hline 5 & Pengamalan agama & 37 & 3 & $97,5 \%$ \\
\hline Jumlah & 166 & 34 & - \\
\hline \multicolumn{2}{|l|}{ Skor maksimum } & 200 & 200 & - \\
\hline \multicolumn{2}{|l|}{ Persentase (\%) } & $83 \%$ & $17 \%$ & - \\
\hline
\end{tabular}

Berdasarkan data pada tabel di atas, Analisis Data Pengalaman Keagamaan diketahui bahwa secara keseluruhan

Pengalaman keagamaan dikumpulkan pengalaman keagamaan mahasiswa $83 \%$ ya, dan $17 \%$ kadang-kadang. Dari data angket pengamalan keagamaan dan aktivitas melalui angket berjumlah 13 item. Data yang telah terkumpul kemudian dianalisis. Hasil mentoring Pendidikan Agama Islam, terlihat bahwa aktivitas mentoring memberi kontribusi dalam pengamalan keagamaan sebesar $83 \%$ atau sebanyak 166 mahasiswa. angket pengamalan keagamaan dinyatakan tinggi apabila lebih dari atau sama dengan nilai median 36, dan dikatakan rendah apabila kurang dari median 36. Hasil angket yang diperoleh adalah sebagai berikut:

Tabel 5. Pengalaman Keagamaan

\begin{tabular}{|l|l|l|l|l|l|}
\hline \multicolumn{2}{|c|}{} & Frekuensi & $\%$ & Valid (\%) & Kumulatif (5) \\
\hline \multirow{3}{*}{ Valid } & Tinggi $\geq 36$ & 28 & 70,0 & 70,0 & 100,0 \\
\cline { 2 - 6 } & Rendah $<36,5$ & 12 & 30,0 & 30,0 & 30,0 \\
\cline { 2 - 6 } & Total & 40 & 100,0 & 100,0 & \\
\hline
\end{tabular}

Berdasarkan tabel di atas, diketahui nilai Lebih jelasnya dapat dilihat dari grafik di pengalaman keagamaan tinggi ada 28 orang bawah ini. (70\%), dan rendah ada 12 orang (30\%). 


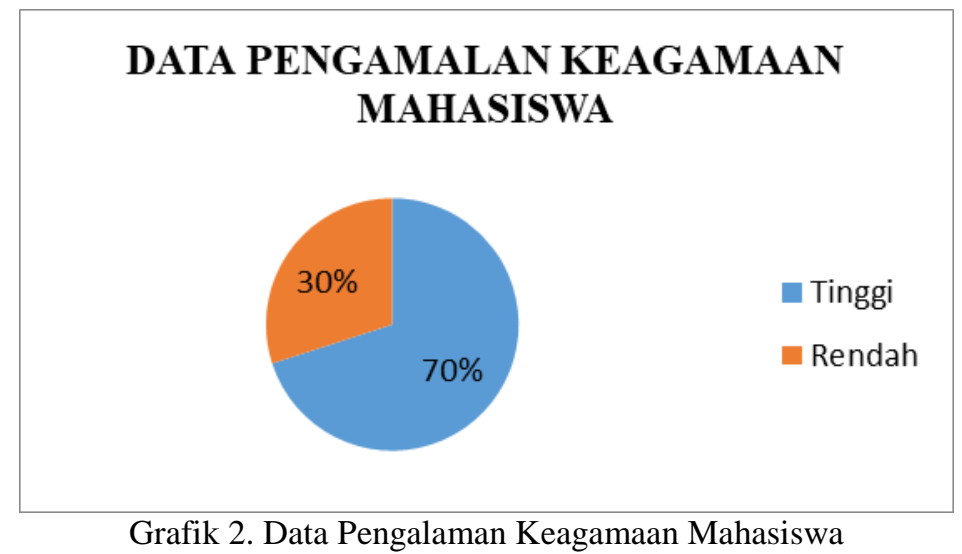

Dari data angket yang telah keagamaan mahasiswa Fakultas Keguruan dikumpulkan, dianalisis dengan uji t. Uji t ini dan Ilmu Pendidikan (FKIP). Hasilnya dapat digunakan untuk mengetahui efektivitas dilihat pada tabel berikut: kegiatan mentoring terhadap pengamalan

Tabel 6. Hasil Uji t

\begin{tabular}{|c|c|c|c|c|c|c|}
\hline \multicolumn{2}{|c|}{ Model } & \multicolumn{2}{|c|}{$\begin{array}{l}\text { Unstandardized Coefficients } \\
\text { s. }\end{array}$} & $\begin{array}{l}\text { Standardized } \\
\text { Coefficients } \\
\text { Beta }\end{array}$ & $\mathrm{t}$ & Sig. \\
\hline \multirow{2}{*}{1} & (Constant) & 20751 & 3,471 & & 00070 & 000 \\
\hline & Pengamalan Keagamaan & 0,724 & 0,099 & 0,766 & 0,343 & 0,000 \\
\hline
\end{tabular}

Berdasarkan tabel di atas diketahui nilai $\mathrm{t}_{\text {hitung }} 7,343>1,70 \quad \mathrm{t}_{\text {tabel, }}$ atau dengan signifikan $0,00<0,05$. Dengan demikian, kegiatan mentoring Pendidikan Agama Islam efektif dilaksanakan untuk menumbuhkan pengamalan keagamaan mahasiswa FKIP Universitas Sriwijaya Palembang.

\section{Pembahasan}

\section{Pelaksanaan Mentoring di FKIP Universitas Sriwijaya Palembang}

Dari pelaksanaan mentoring Pendidikan Agama Islam pada mahasiswa UNSRI Palembang yang berlangsung dalam satu tahun, diperoleh data: Pertama, kegiatan mentoring Pendidikan Agama Islam bertujuan untuk menumbuhkan rasa cinta untuk mempelajari Islam. Tujuan ini dicapai selama kurun waktu dua semester, satu tahun. Pada aspek ini, kegiatan mentoring Pendidikan Agama Islam menghasilkan data 94,6\% berlangsung sesuai harapan. Kedua, tujuan mentoring Pendidikan Agama Islam yang kedua adalah meningkatkan pemahaman Islam yang benar sesuai Alquran dan Sunah Rasulullah Saw. Pada aspek ini, mentoring Pendidikan Agama Islam mencapai tujuan sebesar 90,8\%. Ketiga, tujuan mentoring Pendidikan Agama Islam yang ketiga adalah sebagai partner dosen dalam membentuk mahasiswa yang prestatif dan berkepribadian Islam. Diharapkan, mentoring Pendidikan Agama Islam yang dilakukan dapat berfungsi sebagai partner guru dalam membentuk pelajar yang memiliki prestasi yang baik dan berkepribadian yang sesuai dengan ajaran Islam. Pada aspek ini, ketercapaian tujuan mentoring Pendidikan Agama Islam telah mencapai sebesar 95\%. Keempat, tujuan kegiatan mentoring Pendidikan Agama Islam keempat adalah persaudaraan antar mahasiswa mentoring FKIP UNSRI Palembang. Diharapkan melalui kegiatan mentoring Pendidikan Agama Islam, persaudaraan antar mahasiswa dapat terjalin erat. Dimana, setiap individu dalam mentoring dapat saling bersosialisasi secara santai, bertukar pikiran, dan berkomunikasi dengan baik. Pada aspek ini, ketercapaian tujuan telah mencapai $85,8 \%$. Kelima, kegiatan mentoring Pendidikan Agama Islam diharapkan dapat mencapai tujuan sebagai sarana kaderisasi pelajar muslim untuk mau bergerak menyeruh pada yang ma'ruf dan mencegah yang munkar. Pada aspek ini, tingkat ketercapaian tujuan adalah sebesar 
91,7\%. Keenam, tujuan kegiatan mentoring Pendidikan Agama Islam yang keenam adalah meningkatkan intelektualitas siswa baik dalam bidang keagamaan, akademik dan non akademik. Pada aspek ini, ketercapaian tujuan adalah sebesar 92,5\%.

\section{Pengamalan Keagamaan Mahasiswa}

Pengamalan keagamaan mahasiswa FKIP UNSRI yang dikumpulkan melalui angket adalah sebagai berikut:

Pengamalan keagamaan mahasiswa didasari oleh adanya keyakinan. Keyakinan yang kuat dalam diri individu merupakan sebuah hasil dari pengamalan ajaran agama yang tinggi, semakin yakin individu terhadap ajaran agama maka semakin kuat pula keimanannya, sebaliknya pengamalan ajaran agama yang benar menambah tingkat keyakinan. Materi mentoring Pendidikan Agama Islam dari dosen pembimbing berdampak pada keyakinan mahasiswa. Pada aspek ini, ketercapaian tujuan dalam aspek keyakinan telah mencapai 92,5\%. (2) Suatu ajaran agama yang dipelajari tidak akan berarti apa-apa, jika tidak diikuti dengan praktik yang nyata. Praktik keagamaan adalah gambaran tentang pengamalan ajaran Islam dengan baik dan benar, baik karena dilakukan secara terus menerus benar karena sesuai dengan ajaran agama. Pengamalan keagamaan yang ditanamkan pada mahasiswa dalam program mentoring Pendidikan Agama Islam telah mencapai keberhasilan tujuan sebesar 94,6\%. (3) Pada pelaksanaan ajaran agama terdapat pengalaman keagamaan yang dirasakan oleh individu. Aspek pengamalan keagamaan bertujuan sebagai pengalaman keagamaan mahasiswa. Pada aspek ini, program mentoring Pendidikan Agama Islam yang bertujuan dalam meningkatkan pengalaman belajar ajaran agama pada mahasiswa. Tujuan ini telah tercapai sebesar 96,7\%. (4) Pengamalan agama yang dilakukan juga bertujuan untuk meningkatkan pengetahuan agama mahasiswa. Pada aspek ini ketercapaian tujuan telah mencapai 90,8\%. (5) Pada aspek pengamalan agama, tujuan yang telah tercapai adalah sebesar 97,5\%.
Pengamalan agama merupakan aplikasi atau praktek secara langsung dalam bentuk amal ibadah. Pengamalan agama merupakan bentuk pelaksanaan ajaran Islam.

\section{Efektivitas Program Mentoring}

Penelitian ini bertujuan untuk mengetahui efektivitas kegiatan mentoring Pendidikan Agama Islam terhadap pengamalan keagamaan mahasiswa FKIP Universitas Sriwijaya Palembang. Hasil yang hendak dicapai dari tujuan tersebut adalah, terjadinya perubahan pada diri mahasiswa, setelah mengikuti kegiatan mentoring Pendidikan Agama Islam. Fattah menyatakan, perubahan adalah suatu proses yang menjadikan sesuatu/ situasi yang berbeda dengan yang telah ada (Fattah, 2009). Perubahan yang dimaksud dalam penelitian ini adalah terjadi perbedaan pengamalan keagamaan mahasiswa setelah mengikuti kegiatan mentoring.

Temuan penelitian ini menghasilkan bahwa pelaksanaan kegiatan mentoring Pendidikan Agama Islam efektif dilakukan untuk meningkatkan pengamalam keagamaan mahasiswa di FKIP Universitas Siwijaya Palembang. Hal ini sejalan dengan hasil analisis data menggunakan uji t, nilai $t_{\text {hitung }} 7,343>1,70 \mathrm{t}_{\text {tabel, }}$ atau dengan signifikan $0,00<0,05$. Dengan demikian, kegiatan mentoring Pendidikan Agama Islam efektif dilaksanakan untuk menumbuhkan pengamalan keagamaan mahasiswa FKIP Universitas Sriwijaya Palembang. Dari hasil analisis deskriptif, diketahui persentase kegiatan mentoring sebesar $75 \%$ dan persentase pengamalan keagamaan $83 \%$.

\section{KESIMPULAN DAN REKOMENDASI}

Berdasarkan hasil analisis data dan pembahasan dapat disimpulkan pertama, kegiatan mentoring Pendidikan Agama Islam dalam meningkatkan pengamalan keagamaan telah mencapai keberhasilan secara keseluruhan, sebesar 90\%. Program mentoring dapat mencapai tujuan yang telah direncanakan diawal. Kedua, kegiatan mentoring Pendidikan Agama Islam efektif dilaksanakan untuk menumbuhkan 
pengamalan keagamaan mahasiswa FKIP Universitas Sriwijaya Palembang yang ditunjukkan dengan nilai $t_{\text {hitung }} 7,343>1,70$

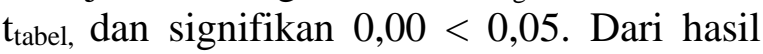
analisis deskriptif, diketahui persentase kegiatan mentoring sebesar $75 \%$ dan persentase pengamalan keagamaan $83 \%$. Dari kesimpulan ini menginformasikan bahwa mentoring sangat efektif dilaksanakan dalam rangka peningkatan pengamalan keagamaan.

Beberapa rekomendasi yang perlu mendapat perhatian dari studi ini adalah pertama, kegiatan mentoring hendaknya dapat dijadikan sebagai salah satu saran dalam meningkatkan pengamalan keagamaan mahasiswa. Kedua, perlu kerjasama dan pengawasan secara terus-menerus, khususnya terhadap alumni mentoring Pendidikan Agama Islam.

\section{REFERENSI}

Ainiyah, N. (2013). Pembentukan Karakter Melalui Pendidikan Agama Islam. AlUlum, 13(1), 25-38.

Basori, A. A. (2013). Pelaksanaan Program Mentoring Agama Islam sebagai Alternatif Pembentukan Perilaku Siswa dalam Pendidikan Berbasis Karakter. Bandung: Universitas Pendidikan Indonesia.

Fattah, N. (2009). Manajemen Perencanaan Pendidikan. Bandung: Alfabeta.

Kurniawati, F. E. (2015). Pengembangan Bahan Ajar Aqidah Ahklak di Madrasah Ibtidaiyah. Journal Penelitian, 9(2), 367-388.

Latifah, N. (2016). Pengaruh Penguasaan Materi Pendidikan Agama Islam dan Hasil Kegiatan Mentoring Agama Islam terhadap Perilaku Sosial Keagamaan Mahasiswa. Yogyakarta.

Luthfiani, E. (2017). Pengaruh Religiusitas Islam Terhadap Kontrol Diri Pada Peserta Mentoring Agama Islam (MAI) di Universtas Andalas. Padang:
Universitas Andalas.

Penyusun, T. (2003). Undang-undang Republik Indonesia nomor 20 tahun 2003 tentang sistem pendidikan nasional. Jakarta: Pemerintah Republik Indonesia.

Penyusun, T. (2006). Asistensi Mata Kuliah Agama Islam. Palembang: Fakultas Keguruan dan Ilmu Pendidikan Universitas Sriwijaya.

Penyusun, T. (2014). Panduan Mentoring Senyum Mentoring, Senyum Kita Semua. Palembang: BSO-Mentoring Nadwah Unsri.

Setiawan, I. (2013). Pengaruh Mentoring Agama Islam Terhadap Perubahan Konsep Diri Mahasiswa Muslim Universitas Sumatera Utara. Medan. Retrieved from http://repository.usu.ac.id/handle/12345 $6789 / 37286$

Shobahiya, M. (2008). Efektivitas Pelaksanaan Program Mentoring alIslam. Ishraqi, 4(1). Retrieved from https://publikasiilmiah.ums.ac.id/xmlui/ handle/11617/1000

Sudaryanti. (2014). Mendidik Anak Menjadi Manusia yang Berkarakter. Jurnal Pendidikan Anak, 3(2).

Wahyudi, I. (2012). Pengaruh Pendidikan Mentoring Al-Islam Dan Kemuhammadiyahan Terhadap Tingkat Keberagamaan Mahasiswa (Studi Kasus Mahasiswa Farmasi Universitas Muhammadiyah Surakarta Tahun Akademik 2010/2011). Surakarta: Universitas Muhammadiyah Surakarta.

Walid, M. (2011). Model Pendidikan Karakter Di Perguruan Tinggi Agama Islam (Studi tentang Pendidikan Karakter Berbasis Ulul albab di Universitas Islam Negeri Maulana Malik Ibrahim Malang). El-QUDWAH, 1(5). 


\section{Article Metadata:}

Nurlaila. Rohayati, E. (2019). The Effectiveness of Mentoring on Students' Religious Practices of the Teacher Training and Education Faculty, Sriwijaya University of Palembang. Ta'dib, 22 (1), 41-50.

http://dx.doi.org/10.31958/jt.v22i1.1431

Keywords: Monitoring Program, Religious Practice, Islamic Education

Coresponding author: Nurlaila, Universitas Islam Negeri Raden Fatah Palembang, nurlaila_uin@radenfatah.ac.id 